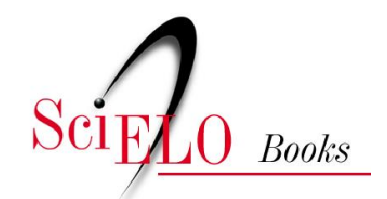

\title{
Geopolítica de la Venezuela Bolivariana
}

\author{
Juan Agulló
}

SciELO Books / SciELO Livros / SciELO Libros

AGULLÓ, J. Geopolítica de la Venezuela Bolivariana. In OLIVEIRA, RP., NOGUEIRA, SG., and MELO, FR., orgs. América Andina: integração regional, segurança e outros olhares [online]. Campina Grande: EDUEPB, 2012. pp. 97-136. ISBN 978-85-7879-185-8. Available from SciELO Books $<$ http://books.scielo.org $>$.

\section{(9)(1)(9)}

All the contents of this work, except where otherwise noted, is licensed under a Creative Commons Attribution-Non Commercial-ShareAlike 3.0 Unported.

Todo o conteúdo deste trabalho, exceto quando houver ressalva, é publicado sob a licença Creative Commons Atribuição Uso Não Comercial - Partilha nos Mesmos Termos 3.0 Não adaptada.

Todo el contenido de esta obra, excepto donde se indique lo contrario, está bajo licencia de la licencia Creative Commons Reconocimento-NoComercial-CompartirIgual 3.0 Unported. 


\title{
Geopolítica de la Venezuela Bolivariana
}

\author{
Juan Agulló
}

\section{Resumen}

Aunque sigue siendo una gran desconocida, Venezuela, da qué hablar. Su Revolución Bolivariana promueve una política exterior anti-imperialista en el marco de una América Latina cambiante. Pese a que Washington siempre se ha sentido incómodo sigue comprando su petróleo ¿Foto fija?

'El petróleo es un arma geopolitica y estos imbéciles que nos gobiernan no se dan cuenta del poder de un pais que produce petróleo'

(Hugo Chávez, en 1997) ${ }^{1}$

\section{Introducción}

Hugo Chávez es una estrella mediática global. Desde que llegó a la Presidencia de Venezuela en 1999 se convirtió en un habitual de los medios de comunicación. Una situación novedosa para un país al que hasta principios de siglo solía

1 Citado por Nicholas Kozloff (2006). 
prestársele una atención muy discreta en la información internacional, pese a ser el séptimo del mundo con mayores reservas de petróleo probadas, noveno productor y cuarto proveedor de Estados Unidos.

Las apariencias, en todo caso, no deben engañar: que, actualmente, la prensa mundial hable de Venezuela y de su Presidente bastante más que en el pasado no quiere decir que los conocimientos globales en torno a dicho país sean mayores que antaño. Las tendencias estructurales lastran: los fondos sobre Venezuela en seis de las bibliotecas latinoamericanistas más importantes del mundo siguen resultando bastante escasos en términos comparados ${ }^{2}$.

Peor: siete de cada diez venezolanistas extranjeros trabajan en Estados Unidos y la mayoría de los académicos venezolanos con proyección internacional tiene algún tipo de relación institucional con dicho país ${ }^{3}$. Consecuencia lógica:

2 Un estudio de fondos bibliográficos, realizado en seis de las bibliotecas latinoamericanistas más importantes del mundo (Biblioteca Hispánica de Madrid ; Bibliothèque Pierre Monbeig del IHEAL de París ; University of Cambridge Library ; Latin American Network Information Center de EEUU ; Biblioteca Central de la UNAM, México y Biblioteca Virtual del Consejo Latino Americano de Ciencias Sociales, Buenos Aires) arrojó los siguientes resultados comparados : Argentina, 14,944; Cuba, 13,591; México, 34,960 y Venezuela, 8,422.

3 .... no cualquier tipo de relación : Universidades del prestigio de Harvard, Chicago, Columbia, Stanford o Princeton suelen acoger, intermitentemente, a algunos de los investigadores sociales venezolanos de mayor prestigio internacional. Georgetown ; Florida International ; Michigan ; Illinois o Iowa también lo hacen. Fuera de Estados Unidos tan solo en Gran Bretaña hay cierta tradición (fundamentalmente en Oxford y Cambridge, alrededor de sus cátedras Andrés Bello y Simón Bolivar). Existe por último, en Venezuela, un caso extremo que merece la pena 
los únicos programas académicos del mundo orientados a Venezuela están en Estados Unidos ${ }^{4}$ y la Sección de Estudios Venezolanos de la LASA tiene su sede en Pensilvanias...

Todo ello implica que - pese al anti-americanismo que caracteriza al chavismo - la mayoría del escaso conocimiento científico internacional sobre Venezuela siga siendo producido - o circule, al menos- por Estados Unidos. Una paradoja típica de muchos países de la periferia que, en el caso de Venezuela, se explica por una estructura académica (docente e investigadora) y editorial (bibliográfica y hemerográfica) especialmente débil en términos comparados ${ }^{6}$.

ser mencionado : el $90 \%$ de los profesores a tiempo completo del IESA de Caracas (centro de formación e investigación, por excelencia, de las clases pudientes venezolanas) se ha formado y/o mantiene algún tipo de relación con Universidades estadounidenses.

4 Dicho programa forma parte del Center for Latin American Studies de la Georgetown University (http://clas.georgetown.edu) y está financiado por la -antichavista- Fundación Cisneros (http://www.orinoco.org/apg/ fundacion.asp?lang=es). No se trata, por cierto, de la única iniciativa de este tipo : la reseñada fundación también financia una cátedra-focalizada, obviamente, en la Venezuela contemporánea- en el muy exclusivo David Rockefeller Center for Latin American Studies de la Harvard University (www.fas.harvard.edu/ drclas).

5 Algunos organismos internacionales también promueven trabajos periódicos sobre la realidad venezolana (el Club de Roma podría constituir un excelente ejemplo al respecto). Si no son aquí considerados es, bien porque sus propuestas no son estrictamente académicas ; bien porque sus metodologías son globales y no se adaptan, específicamente, a Venezuela.

6 En Venezuela hay -planteles universitarios al margen- una veintena de centros de estudio e investigación social que tienen por objeto al propio país : escaso en términos comparados. La estructura organizativa y financiera así como la de propiedad de los mismos son, además, muy variables (van desde aquellos que dependen exclusivamente del financiamiento público hasta aquellos otros que - como el CEDICE 
Hay, en efecto, otros países latinoamericanos - como México, Brasil, Chile, Argentina e incluso, $\mathrm{Cuba}^{7}-$ que al haber alcanzado un grado de desarrollo académico mayor están en mejores condiciones para construir (e incluso, distribuir) conocimiento propio en torno a sus propias realidades. A Venezuela, sin embargo, se le complica: de ahí las dependencias teóricas y como consecuencia de las mismas, las lagunas y estereotipos circulantes...

o el ya citado IESA- lo hacen de consorcios privados que reagrupan a, prácticamente, todos los sectores empresariales del país). Existe, por lo general, escasa coordinación entre dichos centros ; poca unificación de criterios e incluso, duplicación de funciones. Dicho escenario tiene que ver, como ha sido apuntado, con los lineamientos de una política científica nacional relativamente reciente (la puesta en marcha del CONICIT, antecedente del actual FONACIT, data de 1969) caracterizada, además, por una fuerte tendencia a la dispersión. Iván del la Vega (2003) habla de financiación irregular; indefinición de objetivos globales y descoordinación institucional. En este marco, el hecho verdaderamente significativo es que hay áreas estratégicas del conocimiento nacional que, incluso actualmente, quedan sin cubrir por parte de los propios venezolanos. De algunas de ellas, se ocupan organismos extranjeros a través de, fundamentalmente, tres tipos de estrategia : 1) financiamiento a organismos locales (como, por ejemplo, PROVEA) ; 2) financiamiento a delegaciones regionales de grandes organizaciones extranjeras (es el caso de las fundaciones alemanas ; de las agencias de desarrollo europeas y norteamericanas -sobre todo, USAid; de las cámaras de comercio anglosajonas o de otras grandes organizaciones como Amnistía Internacional ; Transparencia Internacional o Conservación Internacional) 3) financiamiento de las delegaciones regionales de algunas de las agencias más importantes de Naciones Unidas como el ACNUR, la FAO, la OMS, el PNUD, el Programa de Población ; la UNESCO o la UNICEF.

7 Un buen ejemplo, cuantitativo, del grado de desarrollo académico e internacionalización alcanzado por cada país podría ser el número de centros académicos afiliados a CLACSO. Para comparar, tomamos los mismos países tenidos en cuenta en la nota $\mathrm{n}^{\circ} 2$ : Argentina, 29 ; Cuba, 15 ; México, 33 y Venezuela, 5. 


\section{La Venezuela no petrolera}

Uno de los clichés más extendidos es que Venezuela es un país eminentemente petrolero. No es que sea falso: sus reservas -aunque algo exageradas- se encuentran entre las más importantes del mundo. Sus ya aludidos niveles de producción son, por otra parte, los culpables de que un $25 \%$ de su PIB; un $80 \%$ de sus exportaciones y un $50 \%$ de sus ingresos fiscales dependan del petróleo.

El país sudamericano, sin embargo, es mucho más que hidrocarburos. En su subsuelo también abundan el oro, la plata, los diamantes, el hierro y el cobre. Además, pueden encontrarse otros minerales de elevado valor estratégico - como el aluminio, la bauxita o el uranio - y otros dos adicionales - como la tantalita o el torio- que aunque

8 Oficialmente, a mediados de 2007, Venezuela tenía unas reservas de petróleo probadas de 80,582 millones de barriles, lo cual ubica al país como el octavo del mundo. A partir de ahí PDVSA - que está embarcada en un proyecto de certificación de las reservas de la Faja Petrolifera del Orinocoasegura que cuando culmine dicho proceso, a las reservas actuales habrá que sumarles 236 mil millones de barriles adicionales. De ser cierto ello colocaría al país con unos 316 mil millones de barriles, como primero del mundo por reservas (actualmente dicho puesto lo ocupa Arabia Saudita, con 262 mil millones de barriles). Dicha posibilidad, sin embargo, no pasa de ser eso, una posibilidad. Más allá de las dudas sobre el posible total de las reservas del Orinoco, hay un elemento aún más inquietante : los crudos de aquella región son, sobre todo, de carácter asfáltico y aunque es verdad que los métodos de refinación mejoran, obtener la certificación internacional tampoco resulta sencillo. De no obtenerse, dichos crudos pueden venderse pero a precios muy inferiores a los de mercado y desde luego, no son considerados como reservas probadas... 
prácticamente todavía no se explotan tienen un valor agregado cada vez mayor en los mercados internacionales?.

Dista de ser todo: el agua es otro de los grandes insumos estratégicos con los que cuenta el país. Cerca de mil ríos, con un potencial hidroeléctrico estimado de $55 \mathrm{mil} \mathrm{Mw}$ (uno de los más altos de América Latina), surcan las fértiles y ricas tierras de un país que, en su vertiente subterránea, está drenado por una sucesión de acuíferos que cubren cerca de 800 mil kms $^{2}$ (90\% del territorio nacional). Detalle clave: el país solo consume un $1 \%$ del agua que posee...

Consecuencia lógica: Venezuela, con sus 25 mil especies vegetales y más de 3 mil 200 animales, forma parte de uno de los siete ecosistemas con mayor biodiversidad del mundo. Ello implica unos elevados índices de endemismo: en el país sudamericano hay más de 200 especies únicas ${ }^{10}$ que habitan en cuatro clusters - o microambientes - diferenciados,

9 Venezuela concentra, por ejemplo, el 12\% de la producción mundial de oro y en cuanto a la potencialidad de otros recursos, sus reservas de hierro frisan los 10 mil millones de toneladas y los de bauxita los 2 mil millones... De la potencialidad de la tantalita (útil para el desarrollo de la tecnología celular) y del torio (útil como combustible nuclear de bajo costo: alternativa al uranio) habla el crecimiento exponencial de su valor agregado a lo largo de los últimos años (Roskill Information Center). A pesar de las cifras, no obstante, nadie debe llamarse engaño: aunque el aluminio es el segundo producto de exportación venezolano, no le genera al país más que un $2.2 \%$ de sus ingresos por exportaciones frente al $80 \%$ del petróleo (CEPAL, 2004).

10 En el caso de las aves, por ejemplo, en Venezuela hay hasta mil 308 especies diferentes: el $40 \%$ de todas las neotropicales conocidas (MARN, 1997). 
algo de lo que no muchos países del tamaño de Venezuela pueden presumir ${ }^{11}$.

Queda la guinda: aunque Venezuela está relativamente poco poblada ( 31 habitantes por $\mathrm{km}^{212}$ ) al tratarse de una economía eminentemente rentista con un mercado de trabajo de reducidas proporciones y un entorno geográfico conflictivo, la mano de obra abunda. Como la calificación media de los trabajadores es estructuralmente escasa y el valor del Bolívar, sucesivamente devaluado, el costo de los factores productivos resulta comparativamente bajo.

¿Cómo explicar, entonces, el monocultivo petrolero? Sencillo: formalidades al margen, la creación de Venezuela como nación es reciente. Dos pilares de su Estado moderno, como el ejército y PDVSA, fueron creados en fechas tan tardías como 1910 y 1974 . Seguramente por eso hay una corriente teórica que siempre ha considerado al país como a un Failed State y otra, más moderada, que subraya las dificultades para la construcción de un proyecto nacional ${ }^{13}$.

11 "Un cluster es un conjunto de atractivos turísticos, infraestructuras y equipamientos, empresas de actividades de ocio y servicios, concentrados en un espacio geográfico homogéneo en cuyo seno tienen lugar las experiencias turísticas" (THR, 2001). En el caso de Venezuela los citados clusters son: el área de costas e islas; la de los Andes y las dos de mayor potencial, los Llanos y sobre todo, la Guayana (que abarca todo el sureste del país, rico en recursos biológicos y mineros y pobre en población).

12 Pese a que la densidad demográfica de Venezuela es algo superior a la de Brasil (24 habitantes por $\mathrm{km} 2$ ), en términos comparativos internacionales, se puede decir que es baja.

13 Failed State (Estado fallido) es un término polémico. Acuñado por la Ciencia Política estadounidense (Noam Chomsky - 2006- es uno de sus principales y más recientes impulsores) se refiere, en principio, a Estados internacionalmente reconocidos cuyos Gobiernos centrales tienen un 
El obstáculo histórico más evidente para asentar la viabilidad política del país radica en una fragilidad institucional directamente relacionada a una enorme segmentación social (tras una década de chavismo, sigue habiendo un $28 \%$ de pobreza). No hay, en efecto, una Venezuela sino dos. No puede decirse, sin embargo, que uno de los dos países viva a costa del otro: más bien, los recursos no son asignados con la equidad y la eficacia debidas. ${ }^{14}$

Un estudio que a principios de siglo pretendía promover el turismo como fuente alternativa de ingresos describe las trabas que lastran al país sudamericano: 'escasa variedad de actividades; mala cantidad y calidad de la información; bajo dominio de los idiomas; insatisfactoria relación calidad/ precio; pocas facilidades de pago; muy escasa profesionalidad del personal; pésima señalización; poco transporte y elevada inseguridad pública' (THR, 2001).

control práctico muy limitado sobre su propio territorio. Desde 2005, la ONG estadounidense Fund for Peace y la revista Foreign Policy publican un índice mundial anual de Estados Fallidos. En 2005 Venezuela ocupó el puesto 55 (de 76); en 2006, el 82 (de 146) y en 2007, el 103 (de 177). Independientemente de los parámetros con los que se calcula dicho índice hay datos que demuestran que, efectivamente, en Venezuela tradicionalmente- los Gobiernos centrales han tenido un control muy limitado de su propio territorio : el $90 \%$ de la población vive, por ejemplo, en las ciudades y el $70 \%$, en la franja costera Norte... La corriente más moderada - que no llega a considerar al país como un Failed State aunque sí subraya las dificultades históricas para el desarrollo de un nacionalismo venezolano-pudiera estar representada por antropólogos como Fernando Coronil (1997) o incluso militares como Emilio Fuentes (1995).

14 Asdrúbal Baptista (1997) recuerda que en Venezuela, petróleo mediante, por cada hora trabajada ise recibe el producto de cuatro! 
En definitiva: personas, ideas y capitales encuentran serias dificultades para circular desde, hacia y por Venezuela, un país cuya economía es, no por casualidad, de las menos productivas y de las menos competitivas del mundo ${ }^{15}$. Pretender, en todo caso, que ello se deba a la orientación socialista del actual Gobierno carece de fundamento: la mayoría de las problemáticas son estructurales y están emparentadas con la especificidad petrolera ${ }^{16}$.

El chavismo - y más allá de éste, los elevados precios internacionales del crudo-a lo único que están contribuyendo es a reforzar (o para ser más precisos, a recuperar) el papel del Estado como agente de desarrollo. En dicho marco, la evaporación - durante los últimos años- de casi dos terceras partes de la inversión extranjera directa ${ }^{17}$, si de algo es indicativo es de un muy débil desarrollo de las fuerzas productivas, típico de una economía rentista.

15 Para muestra, un indicador: el Informe de Competitividad Global 2006/2007 ubica al país sudamericano en el puesto 88 del mundo, $13^{\circ}$ latinoamericano (WEF, 2007).

16 Los cambios estructurales vienen, en efecto, de lejos. El año clave en la reciente historia venezolana fue1960 : en dicha fecha los ingresos por exportaciones petroleras supusieron - por vez primera- la mitad de las exportaciones totales mientras que, la titularidad del capital, fue - también por vez primera- mayoritariamente pública. Ambas tendencias, estructuralmente importantísimas, se debieron al hecho petrolero y no precisamente a decisiones en contra de los intereses privados. Prueba evidente de ello es que, desde entonces - y a pesar de los Gobiernos de signo contrapuesto que se han llegado a suceder- ninguna de ambas tendencias ha variado en lo esencial (Baptista, 2006).

17 Venezuela ocupa un muy discreto noveno lugar en el ranking latinoamericano de inversión extranjera directa - pese a ser el séptimo país por extensión y sexto por población: 1,144 millones de dólares en 2004 frente a 3,683 en 2001 (CEPAL, 2005). 
En pura lógica capitalista, pocos emprendedores se aventurarían a producir en un país en el que -como consecuencia del hecho petrolero - la preeminencia del consumismo sobre la productividad resulta apabullante. Ese es, en efecto, el quid de la cuestión: la rápida monetarización de la actividad económica provocada por la renta petrolera retrae las inversiones productivas privadas. Expresado concisamente: los empresarios prefieren vender antes que producir.

Por eso el Gobierno, en un contexto de bonanza como el actual, se siente obligado a promover un arriesgado desarrollo productivo. Sus predecesores - como toda inversión en rubros no petroleros (recursos naturales o tejido industrial) tiende a redoblar las dependencias petroleras - solían preferir centrarse en la explotación de hidrocarburos reforzando así, indirecta y puede que incluso, involuntariamente, el carácter de reserva geoestratégica del país.

\section{El factor petrolero}

La IV República - creada en plena Guerra Fría, prácticamente en paralelo a la Revolución Cubana - no solo fue alumbrada a partir de dichos planteamientos sino que, como consecuencia de los mismos, reforzó el vínculo entre el mal holandés (que suele desarrollar toda economía dopada por un ingreso brusco y exponencial ${ }^{18}$ ) y la decisión política

18 Mal Holandés es el nombre con el que los especialistas se refieren a las consecuencias dañinas, para una economía, de un brusco - y significativoaumento de los ingresos monetarios de un país. Dicho fenómeno toma su nombre de un artículo en el que Warner Max Corden y J. Peter 
de fundamentar el crecimiento (y por ende, la creación del Estado moderno) casi exclusivamente, en el ingreso petrolero.

Dicha apuesta, sin embargo, comenzó a frisar sus límites cuando los rendimientos petroleros comenzaron a menguar dificultando la -conocida en Venezuela como - siembra del petróleo $^{19}$. Se quebró entonces uno de los principios clave del consenso intraoligárquico que independientemente del régimen político regía el país desde 1918: las regalías ya no bastaban, el Estado necesitaba más ingresos y por ende, muchos más impuestos...

Ante dicho escenario, las petroleras estadounidenses ${ }^{20}$ comenzaron a presionar en pro de una nacionalización, rápidamente asumida por una clase dirigente que terminó anteponiendo sus propias necesidades a las de un Estado en

Neary (1982) analizaron los efectos negativos que, para la economía holandesa, tuvo el descubrimiento - durante la década de los 1960- de grandes yacimientos de gas en el Mar del Norte. En el caso de Venezuela, obviamente, el Mal Holandés tiene una relación directa con los ingresos petroleros. Odalis López analizó en un artículo - en 2001- los efectos de dichos ingresos en la economía nacional durante el periodo 1973-1982.

19 Asdrúbal Baptista (2006) sostiene que el petróleo tiene dos caras, una productiva y otra improductiva. El punto de cruce entre ambas tuvo lugar tras el choc petrolero de 1973: a partir de ese momento el Estado incrementó la dependencia fiscal del petróleo. Con el posterior descenso de los precios internacionales, el déficit fiscal comenzó a adquirir proporciones insostenibles.

20 Inmediatamente antes de la nacionalización petrolera, la mayoría de las petroleras extranjeras presentes en Venezuela eran estadounidenses (sobre todo, Exxon, Shell y Mobil). Ninguna de ellas operaba - durante los últimos años- como tal sino a través de filiales cuyos nombres solían estar compuestos de sufijo - ven. 
construcción ${ }^{21}$. Dicho desliz, aparentemente inocuo, cerró un círculo vicioso, característico de Venezuela: desde entonces el poder quedó - más que nunca - asimilado a la intermediación entre recursos naturales y exportación ${ }^{22}$.

En parte por eso, a largo plazo, la nacionalización de la industria petrolera venezolana (emprendida en 1976, efectiva a partir de $1983^{23}$ ) no terminó resultando tan geopolíticamente determinante como se pensó. El país sudamericano continuó fungiendo, en efecto, de enorme reserva geoestratégica occidental: incluso su perfil en el

21 El incremento del gasto público durante la primera presidencia de Carlos Andrés Pérez (1974-1979), bajo cuyo mandato se nacionalizó el petróleo, fue de un 370\% (Coronil, 1997).

22 Fernando Coronil plantea - frente a lo que suele ser habitual- que dicho proceso se inició, casi desde el comienzo mismo de la explotación petrolera - bajo la dictadura de Juan Vicente Gómez- hacia 1913/1914. Su asentamiento resultó, sin embargo, progresivo. La IV República, al basar su proyecto de modernización en la explotación petrolera, aceleró notablemente el proceso : 1960 fue importante puesto que en dicho año, los ingresos por exportación petrolera superaron, por vez primera, el 50\%. 1976 constituyó, sin embargo, el momento clave ya que convirtió al Estado en intermediador entre las riquezas nacionales y el gran capital transnacional. Por eso a partir de entonces, no controlar la producción de petróleo en Venezuela equivale a no tener un control efectivo del poder como tal.

23 La nacionalización del petróleo venezolano no fue producto de una decisión súbita. Se trató, al contrario, de un largo proceso que arrancó en 1943. Dicho año, bajo la presidencia de Isaías Medina Angarita y bajo la inspiración política de la nacionalización mexicana (realizada por Lázaro Cárdenas seis años antes, en 1937) fue aprobada una Ley de Hidrocarburos (luego de un referéndum) que preveía la no renovación de los contratos de explotación petrolera, el último de los cuales expiraba en 1983. Carlos Andrés Pérez, por consiguiente, lo único que hizo en 1976 fue dotar de sentido político y de viabilidad económica a la medida. 
cártel petrolero internacional (OPEP) terminó por tender a la moderación en los años del Choque Petrolero ${ }^{24}$.

El monocultivo promovido entre 1960 y 1976 había incrementado dramáticamente los términos de la dependencia de Venezuela hacia Estados Unidos. Por eso, un acto aparentemente soberanista como la nacionalización tuvo, en realidad, efectos muy limitados: terminó propiciando una progresiva pérdida de control del país sobre sus propios recursos que prácticamente hicieron desaparecer cualquier atisbo de autonomía en el ámbito internacional.

Seguramente es ahí - y no tanto en la Venezuelan Exception ${ }^{25}$ - donde hay que buscar los motivos de fondo

24 Venezuela jugó un importante papel en la creación de la OPEP, en 1960. De ahí en adelante y hasta la llegada de Chávez al poder, a medida que la dependencia de la economía nacional fue siendo cada vez mayor del petróleo (y específicamente, de sus exportaciones a Estados Unidos) el papel del país dentro de la organización fue moderándose.

25 La Venezuelan Exception (Excepción Venezolana) remite a un viejo debate habido en el seno del venezolanismo (sobre todo, estadounidense) entre - aproximadamente- 1964 y 1994. Steve Ellner y Miguel Tinker Salas retomaron el debate sobre dicho debate -valga la repetición-impulsando y coordinando - en 2005- un número especial (doble) de Latin American Perspectives titulado, precisamente, Venezuelan Exceptionalism Revisited (TDA: El excepcionalismo venezolano en perspectiva). Aseveraban en el mismo que la tendencia a considerar a Venezuela como una excepción en el marco latinoamericano se había basado, fundamentalmente, en tres criterios: 1) los recursos privilegiados del país en relación a su entorno; 2) la ausencia de conflictos, explícitos o latentes, que amenazaran a su estabilidad y 3) la existencia de una cultura política sana y un sistema político sólido. Desde su punto de vista, la Revolución Bolivariana habría demostrado la falsedad de todos esos argumentos. Edgardo Lander, por su parte, apunta -en esa misma revista- que, precisamente, uno de los elementos que demuestran la no excepcionalidad venezolana es la 
de un desinterés internacional tan grande como el que ha existido hacia el país sudamericano, al menos hasta 1999. Internamente, el hecho determinante para comprender esta aparente contradicción es que la directiva asignada a PDVSA desde su fundación compartía filosofía e intereses con las petroleras extranjeras.

No es raro: sus ejecutivos, pese a ser venezolanos, habían sido formados por petroleras estadounidenses como Exxon, Shell o Mobil en el credo del - por entonces naciente neoliberalismo. Precisamente por eso, ese pequeño grupo (de no más de 27 mil ejecutivos en sus momentos álgidos) se planteó desmontar - al principio, en pro de la eficiência - el aparato de control operativo y fiscal trazado por los sucesivos Gobiernos desde 1960.

El resultado fue, a la larga, mucho peor que el insuficiente sistema de regalías al que, en principio, pretendió complementar la nacionalización: a partir de 1983 un ente autónomo como PDVSA comenzó a crecer en el seno del Estado, internacionalizando la compañía casi en la misma medida en la que aislaba y empobrecía al país.

aplicación que hubo en el país de políticas económicas neoliberales, a pesar de no haber padecido - como en otras latitudes- dictaduras militares. Podría añadirse que precisamente eso fue posible por la enorme dependencia estructural -fundamentalmente, de Estados Unidos- que le implicó al país fundamentar su desarrollo moderno (casi exclusivamente) en la explotación de sus recursos petroleros. Dicha dependencia antecedería, por consiguiente, a cualquier tipo de excepcionalidad quedando como específico, exclusivamente, el petróleo, vehículo de la reseñada dependencia. 
El mecanismo financiero fue muy sencillo: importación de costos; exportación de beneficios ${ }^{26}$.

A primera vista, pareciera no tener sentido: los ejecutivos de PDVSA siempre fueron, sin embargo, extremadamente eficaces... Lo que comenzó siendo una sutil resistencia ideológica contra intervenciones gubernamentales (como la realizada, en 1983, para sostener al Bolívar) terminó convirtiéndose en lo que autores como Luis Lander o Bernard Mommer han definido como una simple y llana subversión, soterradamente contrapuesta al nacionalismo militar.

Visto en términos de política internacional, la realidad quizás sea algo más moderada aunque no por ello, más defendible: los ejecutivos de PDVSA, verdadero meollo del

26 La estructura del mecanismo en cuestión fue magistralmente descrita por Juan Carlos Boué, en 2004. Dicho autor definió la internacionalización de PDVSA como 'un programa estratégico de inversiones de largo plazo, encaminadas a integrar verticalmente, a través de la propiedad directa de activos, las actividades de exploración y producción de petróleo de PDVSA en Venezuela con las actividades de refinación, distribución, almacenamiento y mercadeo al detal de productos petroliferos en algunos paises que se cuentan entre los consumidores de petróleo más importantes del mundo'. Para muestra, un botón: un año antes del paro petrolero 19 refinerías venezolanas ubicadas en el área del Caribe, Estados Unidos, Alemania, Suecia, Bélgica y el Reino Unido, recibieron más del $40 \%$ de la producción petrolera nacional. A partir de ese volumen, se generaron 26.927 millones de dólares en ingresos brutos que reportaron unas ganancias de tan solo 638 millones de dólares. ¿Dónde se perdió el resto? Que se sepa: 936 millones de dólares en el descuento que PDVSA le realizaba a sus propias filiales; 517, en reinversión en esas mismas filiales y 298, en impuestos... ¡cobrados por la Hacienda de los países que albergaban dichas filiales! Por consiguiente, solo ese año el fisco venezolano dejó de ingresar, como mínimo, algo más de mil millones de dólares (frisando el endeudamiento externo del país por aquel entonces, los 3 mil millones de dólares). 
poder en Venezuela, tomaron conciencia en algún momento de que la compañía podía sustituir al Estado en la intermediación entre recursos petroleros y exportación... Desde un punto de vista geopolítico (sobre todo, estadounidense) dicha perspectiva, resultaba atractiva...

Se trataba de negociar, no en vano, con personajes ideológicamente afines, no sometidos a fiscalización ni obligación alguna por parte de instituciones supuestamente democráticas como las que regían el país. Despolitización, en suma, de la producción petrolera. ¿Casual que durante aquellos años el precio del crudo venezolano llegara a bajar hasta los 12 dólares $^{27}$ ? ¿Y que la fuga acumulada de capitales doblara el montante total del Plan Marshall28?

Planteamientos éticos al margen, el problema es que mientras todo eso ocurría, el país languidecía: Venezuela, en la práctica, no solo quedó aislada en la escena internacional sino que, económicamente hablando, se vio equiparada a un país no petrolero al que se le complicaba, por añadidura, la explotación de sus otros ricos recursos naturales. Una bomba

27 El petróleo venezolano de exportación (Tía Juana Light : que durante el periodo 1983-1998 se vendió a un precio medio de 21,45 dólares por barril ; frente a los 30,95 dólares del periodo 1999-2007) llegó a cotizar a 12,27 dólares en 1989. En 2007 lo hace a 55,57 dólares.

28 El Plan Marshall fue una iniciativa económica estadounidense para la reconstrucción de Europa tras la Segunda Guerra Mundial. Se desarrolló entre 1948 y 1951, beneficiando a 17 países. El montante total de la suma desembolsada fue de 12,741 millones de dólares, equivalentes a 36,873 millones de dólares de 1999 (189,41\% de inflación acumulada: Federal Reserve, 2007). Según cálculos de Emilio Medina-Smith (2005) la fuga acumulada de capitales en Venezuela rondó, entre 1950 y 1999 , los 70,464 millones de dólares (a precios de 1999). 
social de tiempo: Caracazo en 1989; golpes de Estado en 1992 y Chávez, en 1998.

El saldo de la acción combinada de internacionalización de PDVSA y ajuste estructural interno resultó telúrico: en sólo quince años la pobreza creció en un $617 \%$ y la inflación, en un $50,000 \%{ }^{29}$. Caso internacionalmente equiparable, tan solo, al de países que - como la República Democrática del Congo o la ex Yugoslavia- padecieron cruentas guerras civiles o - como las Repúblicas ex soviéticas- auténticos derrumbes de sus sistemas políticos...

Ese fue el motivo, en parte, de la arrolladora victoria electoral de Chávez en 1999. El verdadero vuelco político se produjo sin embargo cuando, en 2003, el actual Presidente logró desarmar el paro petrolero haciéndose, a continuación, con el control de PDVSA. El exponencial incremento, en 2004, de los precios internacionales del petróleo asentó su poder favoreciendo, de paso, la reinternacionalización de Venezuela ${ }^{30}$ : el escenario había cambiado...

29 En el caso de la pobreza, cálculos propios a partir de datos del Banco Central de Venezuela y en el de la inflación, los datos son de Leonor Filardo (2007).

30 Hay tantas teorías sobre el incremento de los precios del petróleo a partir de 2004 como sobre el Golpe de Estado en Venezuela de 2002. Seguramente sea necesario esperar a la apertura de determinados archivos para conocer, en un futuro, la realidad de los hechos. Lo que aquí nos interesa subrayar son, sin embargo, las teorías que ligan el Golpe de Estado y el posterior Paro Petrolero a la Guerra de Irak. Los que las sostienen argumentan que, al principio, George W. Bus habría tratado de financiar dicho conflicto de forma parecida a como lo hizo su padre, en 1991, con la Guerra del Golfo: sacando el petróleo - en este caso, venezolano: vía Golpe de Estado - del mercado en aras de generar una elevada prima petrolera que, una vez reintroducido el petróleo iraquí en 


\section{La política exterior chavista}

Tras una desaparición forzada de una veintena años (19832003), Venezuela volvió al escenario internacional tan solo cuando su Estado logró recuperar un papel de intermediador entre los recursos petroleros del país y el gran capital transnacional, es decir, cuando logró repolitizar las relaciones petroleras. Una maniobra clave al respecto previa al cierre patronal de 2002/2003 fue la apuesta por una recuperación del carácter de cártel de la OPEP ${ }^{31}$.

El primer Chávez, pese a las apariencias, tendió a la moderación $^{32}$. Sin embargo, el 11-S en Estados Unidos

el mercado, le permitiera a Washington tener un control político de la producción, tanto en Irak como en Venezuela. Sea o no cierto, lo curioso del caso es que la realidad de los hechos - cuatro años después - es que Estados Unidos no controla ni una ni otra producción y que, además, si hay un beneficiario de la prima petrolera en el mundo, ese es Caracas.

31 La OPEP, que a mediados de la década de los 1990, había visto reducida al mínimo su influencia en la política internacional volvió a recuperarla a partir de los años 2001/2003. La propaganda oficial venezolana atribuye dicho logro a la actividad política y diplomática desplegada por Hugo Chávez en el seno de la organización desde 1999. Aunque hubo toda otra serie de factores que determinaron dicha deriva (como la pérdida de peso de los países productores de petróleo no miembros de la OPEP o las dificultades estadounidenses para volver a introducir el petróleo iraquí en el mercado internacional) lo cierto es que la cohesión en el interior del cártel se ha incrementado notablemente: en qué medida ello se deba al exponencial incremento de los precios internacionales del petróleo o a las iniciativas chavistas es algo difícilmente mesurable...

32 Hablar de moderación del chavismo primigenio no es retórico... Durante una entrevista realizada en 2005 el propio Chávez reconoció que, antes, no había sido socialista: '[...] llegué a mencionar como referencia la llamada Tercera Via, una de las tesis de Tony Blair [...] Llegué a pensar en un capitalismo con rostro humano, o el capitalismo social, una tercera vía 
y el Golpe de Estado de 2002 en Venezuela alteraron las circunstancias: de hecho, aunque todavía subsisten ciertas dudas sobre el papel de Washington en su intento de derrocamiento ${ }^{33}$, una vez logrado el control de PDVSA, Chávez mudó rápidamente su multilateralismo en antiimperialismo y su blairismo en socialismo.

Emprendió entonces una política exterior tendiente a reposicionar a Venezuela en el mundo. Ello había de pasar, desde su perspectiva, no solo por la promoción de un proceso de reconstrucción nacional, sino por una redefinición geopolítica de América Latina que debía aprovechar una coyuntura favorable: Estados Unidos estaba entrampado en dos guerras asiáticas y Brasil, aspiraba a un papel internacional (y latinoamericano) cada vez más activo ${ }^{34}$.

entre socialismo y capitalismo. El paso de los años me convenció que eso era imposible: un capitalismo humano es una contradicción en si mismo'.

33 Un lustro después del Golpe de Estado de 2002 todavía resulta aventurado realizar afirmaciones tajantes con respecto al mismo. Varios de sus actores continúan en puestos de responsabilidad en sus respectivos países... Aunque algunos documentos oficiales ya se han llegado a conocer, la mayoría, todavía tardará años (por no decir, décadas) en ser públicos... Se puede hablar, por lo tanto, de grandes tendencias (como la evidente connivencia de Washington en la acción: Forero, 2004) pero sería demasiado aventurado desmenuzar los matices... Desde entonces, mucho ha sido publicado - sobre todo en Venezuela- pero, poco, debidamente fundamentado. La mayoría son conjeturas. Desde aquí remitimos a un par de documentos, relativamente diferentes: la comparecencia del ministro español de Asuntos Exteriores ante el parlamento de su país para dilucidar el papel jugado por España en el Golpe (por tratarse de un documento oficial) y un libro editado por la Defensoría del Pueblo de Venezuela en 2003 (por tratarse de una institución oficial).

34 Después del 11-S, en menos de dos años, Estados Unidos se vio involucrado, sucesivamente, en dos guerras asiáticas (Afganistán, 2001 e Irak, 
El latinoamericanismo militante (amén de la política petrolera) debía fungir, por consiguiente, de guía pero, también, de garante de la nueva política exterior venezolana. De hecho, esta última debía orientarse a promover la integración regional pero, también, a cobijarse tanto en las relaciones bilaterales como, sobre todo, en las estructuras multilaterales autónomas que podían/debían constituir su consecuencia más tangible.

La pretensión última del chavismo consistía en sortear las limitaciones objetivas de ser un país relativamente pequeño, poco poblado y estructuralmente dependiente para convertirlo en una referencia (geopolítica pero, también, ideológica) tanto en el marco latinoamericano como, incluso, en el mundial. De ahí que, el principio que siempre ha alimentado la Diplomacia Bolivariana sea una fraternidad entre los pueblos traducida en realizaciones concretas.

Dichas realizaciones se estructuran, fundamentalmente, a dos grandes niveles: uno, simbólico y el otro, financiero. El nivel simbólico tiene que ver con la pretensión chavista de erosionar la hegemonía estadounidense, sobre todo en América Latina. Aquí es donde la inspiración antiimperialista adquiere una dimensión, incluso, estratégica:

2003) que, al afectar seriamente al déficit público de Washington, algunos autores se han atrevido a situar en la génesis de la crisis financiera que estalló en 2008. 2003 fue, por otra parte, el año de la llegada de Luiz Inazio Lula da Silva a la Presidencia de Brasil, que marcó un giro considerable en la política exterior de dicho país: una presencia, mucho más activa que antaño en América Latina y al mismo tiempo, una intensa e inédita promoción de relaciones Sur-Sur (fundamentalmente, a través de iniciativas como los BRICS, etc.). 
tanto en el ámbito del altermundismo como, sobre todo, en el de la izquierda latinoamericana.

La asociación estratégica de Venezuela con Cuba ${ }^{35}$ resulta clave en este sentido. De hecho, la dimensión bilateral de la misma resulta interesante pero más lo es, si cabe, su dimensión simbólica. De hecho, dicha relación, no solo ha contribuido a dotar de legitimidad y de credibilidad al chavismo en ciertos sectores de la izquierda mundial sino que ha propiciado un marco maniqueo de referencia en el que, Chávez, siempre se ha movido muy a gusto ${ }^{36}$.

El nivel financiero, por otra parte, es sólo petrolero en origen. De hecho, la Venezuela chavista está llevando a cabo una utilización muy racional de sus recursos: promoviendo sobre todo en el ámbito latinoamericano - iniciativas políticas basadas en heterodoxos intercambios (como el ALBA o

$35 \mathrm{El}$ instrumento jurídico que regula dicha asociación es un Convenio Integral de Cooperación suscrito entre Caracas y La Habana en 1999 y renovado cada cinco años. La relación entre ambos países se fraguó, en realidad, desde mucho antes: apenas salido de la cárcel, uno de los primeros países visitados por Hugo Chávez fue Cuba. Posteriormente, momentos como la Tragedia de Vargas (1999) o el Golpe de Estado de 2002 contribuyeron a asentar una relación que a Cuba también le resulta estratégica. El Convenio establece, no en vano, el suministro de petróleo por parte de Venezuela a cambio de asistencia técnica en diversas áreas, sobre todo sociales. Según un cálculo realizado por el anti-chavista periódico El Universal (Párraga, 2005) Venezuela le habría suministrado a Cuba, en los cinco primeros años de vigencia del Convenio, el equivalente a 850 millones de dólares.

36 Esto se puede resumir muy bien en una frase que se convirtió en clave, durante el referéndum revocatorio de 2004: "O conmigo [con Chávez] o con Bush". 
PetroCaribe ${ }^{37}$ ) y afianzando relaciones no tradicionales con países no latinoamericanos mediante la utilización de novedosos instrumentos financieros.

La intención geopolítica última de iniciativas como el ALBA o PetroCaribe es, por su parte, doble. De hecho, se trata de una estrategia encaminada a propiciar un blindaje diplomático pero, también, político de la Venezuela Bolivariana $^{38}$ que, al mismo tiempo es útil para potenciar

37 La Alianza Bolivariana para los pueblos de Nuestra América-Tratado de Comercio de los Pueblos (conocida como ALBA) es una organización internacional, promovida por Venezuela en el ámbito latinoamericano que fue creada en 2004 como alternativa al Área de Libre Comercio de las Américas (ALCA: promovida por Estados Unidos desde 1994). Con el paso de los años se ha convertido en una instancia de cooperación entre ocho países latinoamericanos y caribeños (más algunos otros satélites) que, además, está actuando como grupo de presión independiente en el seno de instituciones oficiales de integración regional como la Unión de Naciones Sudamericanas (UNASUR). Para Venezuela, su valor político está siendo invaluable ya que le está permitiendo redoblar su influencia internacional por medio de un ejercicio, constante, de representación.

PetroCaribe es, por su parte, una iniciativa complementaria con la anterior. Legalmente hablando funciona como una acuerdo de cooperación energética entre siete países del área del Caribe y Venezuela. En lo básico, Caracas, provee a los países miembro de petróleo a precios espaciales a cambio, no solo de dinero sino de otro tipo de mercancias y saberes. Mucho se ha discutido sobre si éste es un acuerdo que le convenga, económicamente hablando, a Venezuela. Políticamnete hablando, no cabe duda: Caracas está logrando institucionalizar una influencia nunca antes soñada en el área del Caribe que tiene un valor diplomático (pensando en posibles votaciones en el marco de Naciones Unidas) pero, también estratégico.

38 Una de las obsesiones de Hugo Chávez es evitar, en la medida de lo posible, un intento de Golpe como el de 2002. Ese es el motivo por el que, desde entonces, se ha procedido a un blindaje estratégico del paíse que también afecta a su política internacional. La idea básica es poder 
la capacidad de influencia de Caracas en el marco de un abigarrado proceso de integración latinoamericana (que pivota alrededor de UNASUR y de MERCOSUR).

Por cuanto se refiere a la política no latinoamericana de Caracas ésta tiene, fundamentalmente, dos grandes principios rectores. Sus vectores son tanto los países productores de hidrocarburos (Venezuela, no solo contribuyó a la reactivación política de la OPEP sino que, a partir de 2001, comenzó a promover la creación de un Foro de Paises Exportadores de Gas $^{39}$ ) como los paises emergentes o aquellos definidos por Washington como Rogue States ${ }^{40}$.

contar, en casos extremos, con apoyos diplomáticos muy firmes. En ese contexto es en el que hay que leer el desarrollo de iniciativas que - como el ALBA o PetroCaribe- ligan los intereses nacionales de diversos países vecinos a los de la propia Venezuela e incluso, los institucionalizan.

39 El Foro de Paises Exportadores de Gas (FPEG) se planificó, desde un primer momento, como una especie de "OPEP del gas": con los mismos principios y los mismos objetivos de dicha organización. Lo interesante del asunto es que, en este caso, Caracas logró involucrar en la idea a un país gasífero de peso como Rusia. Al final, una veintena de Gobiernos terminaron reuniéndose a partir de 2001. Pese a la importancia geopolítica de la iniciativa y a que la FPEG, formalmente no ha desaparecido, lo cierto es que en los últimos años se ha estancado un poco. Su potencialidad geopolítica se encuentra, empero, fuera de toda duda.

40 Rogue State es un controvertido término desarollado por los neo-con estadounidenses durante la presidencia de George W. Bush (2001-2008). En español ha sido traducido como Estado Canalla. Teóricamente se refiere a países, presuntamente autoritarios e incluso violadores de los Derechos Humanos que además serían políticamente enemigos del llamado mundo libre. Irán, Sudán, Siria o Corea del Norte se encuentran entre los países que gozan del dudoso honor de haber sido considerados como tales. En el pasado Afganistán, Irak y Libia, también compartieron dicho calificativo. Como se podrá observar, la mayoría de ellos padecieron guerras o en todo caso, actitudes políticas muy hostiles por parte de Estados Unidos y de sus aliados. 
La relación con los primeros le garantiza a Caracas el mantenimiento de unos elevados precios de sus hidrocarburos que le permite, no sólo mantener intacta su influencia política en América Latina, sino seguir financiando el ya citado proceso de reconstrucción nacional. Por su parte, la relación con los países emergentes y con los Rogue States le aportaría a Venezuela, respectivamente, seguridad estratégica y prestigio político ${ }^{41}$.

Lo interesante aquíson, en todo caso, los instrumentos que la Venezuela chavista está utilizando para afianzar las relaciones diplomáticas que considera más importantes (incluso en el ámbito latinoamericano). Se trata, fundamentalmente, de los llamados Fondos Soberanos ${ }^{42}$, una herramienta financiera

41 Los países emergentes (como China, India, Rusia o Brasil, entre otros) le aportarían a Venezuela seguridad estratégica en la medida en la que su peso económico e incluso, militar, va en aumento a escala global. Desde la perspectiva chavista, los Rogue States aportarían prestigio, fundamentalmente, entre algunos países del Sur e incluso desprestigio entre la mayoría de los Occidentales, cosa que no siempre le disgusta a Chávez. Ambas percepciones estratégicas deben ser entendidas en el marco de los intentos de blindaje político que Caracas está pretendiendo a escala internacional desde el intento de Golpe de Estado de 2002.

42 Los Fondos Soberanos (en inglés, Sovereign Wealth Founds) son unos instrumentos financieros de inversión que suelen ser de titularidad pública. En términos generales su capital suele provenir de ingresos extraordinarios por commodities (en la mayoría de los casos, aunque no en todos, del petróleo). El primero en existir en el mundo fue la Kuwait Investment Authority, en 1953. Desde entonces, los fondos, han sido creados en oleadas sucesivas: una primera en el marco del schock petrolero de la década de los 1970 y una segunda, en el marco de la crisis financiera global actual. Su utlidad es grande ya que suelen servir muy bien para proteger (e incluso incrementar) los ingresos de un país y para financiar, en la mayoría de los casos, su desarrollo. El primer fondo de estas características en ser creado en América Latina fue el Fondo de 
que no solo está permitiendo reinvertir inteligentemente los petrodólares sino ligarlos, en términos bilaterales, al problema del desarrollo.

La politica exterior chavista es, en definitiva, una estructura compleja y aunque muy discutida en algunos aspectos (sobre todo, en Europa y en Estados Unidos) tiene, no sólo una racionalidad de fondo sino una relación estrecha con la coyuntura política interna de Venezuela. Sus objetivos finales pivotan alrededor de un único fin: afianzar la reconstrucción nacional reduciendo para ello (o más bien, diversificando) dependencias difícilmente superables.

Si eso se está logrando o no, es otra cosa. De hecho uno de los aspectos más contradictorios de la política exterior chavista es que de momento, Venezuela, no sólo continúa alimentando el tanque de un país que - como Estados Unidos - mueve un tercio de la maquinaria capitalista mundial sino que, por mucho que la diversificación se haya convertido en un prioridad, sigue sentando, a diestra y a siniestra, las bases de un desarrollo capitalista global insostenible.

\section{La política de Estados Unidos hacia Venezuela}

Desde Washington, el chavismo en general y su política exterior en particular, siempre han sido contemplados con una mezcla de incomprensión y desprecio. En términos generales, se trata de un tema que siempre ha preocupado más

Estabilización Socioeconómica chilena, en 1985 (sus fondos provienen de los ingresos por cobre). Venezuela fue el primer país latinoamericano en crear un fondo soberano ligado a los ingresos petroleros, en 1998. 
de lo reconocido, que es menos de lo que Caracas pretende ${ }^{43}$. Pese a todo, las visiones nunca han sido uniformes en Estados Unidos: los especialistas (sobre todo, los académicos) los gobernantes y los medios nunca han solido coincidir.

Quizás por eso, en la década larga que Chávez lleva en el poder, la política de Estados Unidos hacia Venezuela ha carecido de un rumbo definido. De hecho, las consideraciones tácticas siempre han solido primar sobre las estratégicas. $\mathrm{Al}$ principio - desde el final de la Presidencia de Bill Clintonse operó a partir de la Doctrina Maisto (del nombre del ex embajador John Maisto: 1997-2000): 'No juzgar a Chávez por lo que dice sino por lo que hace'.

Por aquel entonces se pensaba que las dependencias estructurales de la economía venezolana hacia Estados Unidos - urdidas desde la década de los $1930^{44}$ - mantendrían a Chávez dentro de unos límites ${ }^{45}$. Una visión coherente con

43 Para muestra, dos -aparentemente- contradictorios botones: en 2006 no hubo (a pesar de ser año electoral en Venezuela) ninguna audiencia monográfica sobre dicho país en la poderosa comisión de Relaciones Exteriores del Senado estadounidense (tampoco en lo que va de 2007: http://foreign.senate.gov/hearing.html). Ese mismo año, sin embargo, Washington anunció la creación de una misión especial de la CIA para supervisar las operaciones de inteligencia de Cuba y Venezuela: un honor que solo comparte una veintena de países, considerados por el NIC como los más inestables del mundo (CIA, 2006).

44 Janet Kelly y Carlos A. Romero (2002) describen a la perfección dicho proceso.

45 Hay un ejemplo que ilustra la forma de pensar que tenían los responsables políticos y diplomáticos estadounidenses, incluso, años después de la enunciación de la Doctrina Maisto. En junio de 2002, apenas dos meses después del Golpe de Estado, Julia E. Sweig (responsable del área para América Latina de la Fundación Rockefeller y consultora del 
la política latinoamericana de distensión y de libre comercio introducida en América Latina por un Gobierno más ligado a capitales tecnológicos y a energías renovables que a la industria pesada y a los recursos no renovables.

A George W. Bush le sostuvo, por el contrario, la industria pesada que se nutre, precisamente, de recursos no renovables. Siendo más claros: él mismo pertenece a una familia petrolera. Por eso es lógico que, aunque después de 2001, Washington siguiera sin definir claramente una posición estratégica con respecto a la Venezuela chavista, endureciera su posición táctica. Más aún tras el 11-S y las guerras de Afganistán y sobre todo Irak, otro país petrolero...

Se abrió así una etapa de intervencionismo que pudiera ser calificado de indirecto, en la medida en la que las fuerzas armadas estadounidenses nunca llegaron a estar formalmente involucradas ${ }^{46}$. Salvo por un embargo inexistente, el modelo

CFR) escribió en Los Angeles Times: 'La antipatía de Washington hacia Chávez puede ser más ideológica que sustantiva. Bajo Chávez, Venezuela ha tomado decisiones del agrado de Washington. Nunca ha existido una amenaza real de corte del suministro de petróleo venezolano hacia Estados Unidos, que representa aproximadamente el $14 \%$ de las importaciones petroleras estadounidenses. La compañia telefónica ha sido privatizada (sic) y la moneda, devaluada. Caracas colabora con el Fondo Monetario Internacional y otras agencias multilaterales y sigue cooperando en la lucha contra el narcotráfico y otros asuntos de inteligencia. Además, recientemente, el Comando Sur del ejército de Estados Unidos ha reconocido que no hay evidencias de apoyo venezolano a la guerrilla más importante de Colombia'.

46 Resulta muy interesante, en este sentido, la polémica desatada por la realización - en mayo de 2001: justo un año antes del Golpe de Estado- de la Operación Balboa, unos ejercicios militares promovidos por España (en los que participaron, también, Colombia y Panamá) que se planteaban una posible invasión del Occidente de Venezuela (fueron realizadas en las 
aplicado presentó ciertas similitudes con la política cubana de Washington, especialmente, con la posterior al derrumbe de la Unión Soviética. Hay evidencias de que el lobby cubano-americano influyó al respecto ${ }^{47}$.

cercanías de la isla de Curaçao) en el marco de una supuesta situación de guerra. Estados Unidos, teóricamente, no participó en dicha operación aunque, según la investigadora Eva Golinger (2006) hay múltiples indicios que involucrarían a su Gobierno quien habría podido, incluso, incitar a la mismísima realización de las referidas maniobras.

47 Los indicios de la participación estadounidense (sobre todo, financiera) en acciones de desestabilización en Venezuela son numerosos, sobre todo, desde 2001. Menos estudiado ha sido, sin embargo, el papel político jugado en las mismas (sobre todo, en términos de cabildeo) por el lobby cubanoamericano, aliado de la colonia venezolana en Florida (que supera, ya, los 160 mil individuos; está organizada en, al menos, dos grandes asociaciones - IVAC y ORVEX- y ya cuenta, incluso, con una sección específica en $E l$ Nuevo Herald, el gran periódico de la comunidad cubano-americana). Méndez y Buajasén (2006) aportan interesantes datos teóricos sobre los métodos de funcionamiento político-institucional de dicho grupo de presión. Artículos más periodísticos como los de Casto Ocando (2002) resultan, por su parte, muy elocuentes: 'Los venezolanos y los cubanos han realizado durante casi tres años una gran cantidad de actividades en conjunto, para reforzar la protesta internacional en contra de lo que califican de la pesadilla chavista. Con frecuencia se organizan reuniones en locales de los grupos cubanos, se intercambian permisos de protesta, y es normal ver a venezolanos y cubanos protestando juntos en el consulado de Venezuela en la avenida Brickell, o ante el busto de Simón Bolivar en Bayside. La ayuda del exilio se ha traducido también en apoyo logistico y de cabildeo ante organismos como la OEA y la ONU, adonde organizaciones venezolanas han denunciado al gobierno de Chávez' Cabe añadir que en los últimos tiempos dicha relación ha comenzado a generar frutos: en marzo de 2007 los congresistas Lincoln Díaz-Balart; Ileana Ros-Lehtinen; Mario DíazBalart; Connie Mack y Jerry Weller (todos ellos cubano-americanos o ligados al lobby cubano-americano) solicitaron al Presidente George W. Bush una protección migratoria especial a favor de los venezolanos. Su concesión podría implicar una alteración sustancial del estatus político oficial del país sudamericano en Estados Unidos... 
Esta ideologización de la relación bilateral no estuvo exenta de consecuencias: fue el momento en el que los conocimientos académicos estadounidenses resultaron más divergentes con las decisiones políticas asumidas por Washington. Primaron, al igual que en el caso cubano, los estereotipos y las acciones de desestabilización basadas en errores de cálculo: la cúspide de dicha conducta coincidió con el fallido Golpe de Estado de 2002.

Es muy probable que la decisión de promoverlo - o al menos, de alentarlo - fuera tomada por un equipo de halcones en función de evaluaciones de campo inexactas ${ }^{48}$ (especialmente en lo concerniente al apoyo social real con el que contaba Chávez). Como consecuencia de ello, al igual que posteriormente sucedió en Irak, el margen de maniobra

48 Existen múltiples pruebas (a las que se ha aludido previamente) que demuestran que Washington sabía que iba a haber un Golpe de Estado en Venezuela, en abril de 2002. En su momento lo denunció, incluso, el The New York Times (Forero, 2004). El único extremo que, quizás, todavía queda por averiguar es hasta dónde llegó la implicación política real de Washington: ¿promovió el Golpe; solo lo amparó ; lo promovió primero y lo amparó después o se trató, tan solo, de elementos aislados ? Ocurriera lo que ocurriera, hay algo evidente : la actitud condescendiente de Washington debió estar marcada por el equipo de halcones que dirigía - sobre todo en el momento del Golpe- la política latinoamericana del Gobierno de George W. Bush. Caracas siempre ha apuntado, fundamentalmente, a tres personajes : el actual adjunto a la Secretaria de Estado, John Negroponte (ex embajador en Irak y en Naciones Unidas y gran urdidor, en la década de los 1980, de la Contra nicaragüense); Roger Noriega (ex embajador ante la OEA y ex responsable de asuntos latinoamericanos : 2003-2005) y Otto Reich (cubano-americano ; ex embajador en Venezuela : 1986-1989 y ex enviado especial del Presidente Bush a América Latina). 
del Gobierno de Bush se vio reducido: si alguien salió políticamente fortalecido del Golpe, ese fue Chávez...

Dicha situación determinó cierto reflujo en la presión política estadounidense que abrió espacios para la realización de análisis, más actualizados y precisos, sobre Venezuela ${ }^{49}$. Washington fue comprendiendo que las informaciones de inteligencia no eran suficientes para aprehender la naturaleza del chavismo y que, además, los líderes opositores eran poco fiables. Los resultados obtenidos por Chávez durante el referéndum de 2004 confirmaron las sospechas ${ }^{50} \ldots$

Coincidiendo con el inicio del segundo mandato presidencial de Bush (y con la intensificación del conflicto en Irak) el intervencionismo indirecto en Venezuela tendió a diluirse en una suerte de bilateralismo intensivo, caracterizado por una presión mucho más focalizada que la empleada desde 2001. De hecho, a partir de ese momento, los grandes temas

49 A partir de 2004, en efecto, en Estados Unidos comenzaron a aparecer investigaciones sociopolíticas orientadas, más que a ampliar los conocimientos con respecto a Venezuela, a actualizarlos. A moderados y halcones les unía la imperiosa necesidad de abandonar la vieja perspectiva de la Venezuelan Exception. Se actuó a diversos niveles: gubernamental (secretaría de Estado, ejército y servicios secretos); universitario (Universidades de Miami, Internacional de Florida, Texas, etc.); ideológico (think tanks como el Council on Foreign Relations, el North American Congress on Latin America; la Heritage Foundation; el Council on the Americas; el Council in Hemispherics Affairs e incluso, la World Future Society) y editorial (revistas como Latin American Perspectives, Foreign Affairs o Foreign Policy). [los más significativos se encuentran citados en las Fuentes].

50 Hugo Chávez obtuvo en el referéndum revocatorio -celebrado el 15 de agosto de 2004- 5,800,629 votos a su favor $(59.10 \%$ de los votantes: 30.08\% de abstención: <www.cnegov.ve>). 
fueron el narcotráfico; el terrorismo; los derechos humanos, la democracia y un acoso político sutil pero constante ${ }^{51}$.

Ello permitió que, poco a poco, un discurso más coherente con respecto a Venezuela - formulado por nuevos actores ${ }^{52}$ - comenzara a filtrarse en Washington: ya no se trató de estructurar la relación bilateral, como con Clinton, alrededor del parámetro petrolero sino de abrir el juego alertando de una presunta degradación de la calidad de la democracia amén de la creación de supuestos santuarios de la narcoguerrilla colombiana al suroeste del país.

51 Las acciones de acoso político incluyeron, no en vano, desde financiamiento a grupos opositores (que, tras el Golpe de Estado, se institucionalizaron -a través de la USAid- y se diversificaron) hasta maniobras militares realizdas por países aliados (como la ya citada Operación Balboa) pasando por la instalación o refuerzo de bases estadounidenses en áreas cercanas a Venezuela (como Aruba y Curaçao); la - también referida- apertura de una misión de inteligencia encargada de Cuba y Venezuela o incluso el diseño de Mercenaries 2, World in Flames (www.mercs2.com) un videojuego en el que un comando militar tiene que tomar por asalto una refinería de un país tropical. El trabajo que el jugador ha de llevar a cabo forma parte, en realidad, de una misión más amplia: garantizar el control del petróleo, que se encuentra en manos de un tirano local...

52 Un punto interesante a este respecto: Thomas A. Shannon, máximo responsable de las políticas latinoamericanas de Estados Unidos desde 2005, conoce Venezuela mucho mejor que su predecesor - Roger Noriega- entre otras cosas porque fue consejero político de la Embajada estadounidense en Caracas, precisamente, cuando John Maisto era Embajador (1996-1999). Su declaración en el sentido de que la democracia venezolana se encuentra en grave peligro (2005) demuestra su evolución personal pero también - si lo comparamos con el tono de relativa moderación imprimido a las relaciones de Washington con Caracas - cierto grado de adaptación política subrayado, incluso, por Lapper (2006). 
Independientemente de la falsedad de dichas acusaciones, lo importante del referido planteamiento es que, en la práctica, terminó dotando de una base política a la intransigencia de Washington. Lo relevante de dicha actitud es que, aunque siguió sin acompañarse de estrategias de largo plazo, comenzó a tener repercusiones mediáticas, sobre todo, en el ámbito Occidental: fue entonces cuando la imagen de Chávez como dictador comenzó a calar en la prensa.

Dicho "logro", sin embargo, nunca proporcionó resultados reales. Quizás por eso - coincidiendo con la segunda reelección de Chávez y el ocaso de la segunda Presidencia de Bush hijo - apareció la Doctrina Lapper ${ }^{33}$ que, en lo básico, planteó una desideologización de la relación entre ambos países. En la práctica, se trató de una ofensiva de los sectores más tecnocráticos de la clase dirigente orientada a la recuperación de posiciones políticas más pragmáticas.

No por casualidad, la referida Doctrina argüía que aunque en la medida en la que Chávez había ido acumulando recursos, había ido logrando que sus dichos coincidieran con sus hechos, los límites de Caracas seguían estando marcados por un bien fluctuante y no renovable como el petróleo que hacía que la dependencia económica de Venezuela hacia Estados Unidos, medida en términos estructurales, siguiera sin desarticularse por completo ${ }^{54}$.

53 Dicha Doctrina tomó el nombre de Richard Lapper, un analista del Council on Foreign Relations, un poderoso think-tank, de carácter bipartisano, centrado en política exterior.

54 Lapper (2006) desgrana varias razones. Argumenta, para empezar, que el crecimiento económico de Venezuela no es sostenible a largo plazo porque depende en una proporción determinante de un bien fluctuante 
La conclusión de todo lo anterior era que, seguir promoviendo un cambio de régimen en Venezuela como estrategia política casi única, podía resultar contraproducente. Es más, que el aislamiento de Venezuela debía ser evitado: había que manejar bilateralmente los temas estratégicos y ubicar la comprensión del chavismo como fenómeno sociopolítico en el marco del giro a la izquierda ocurrido en América Latina desde finales de los años 1990.

En términos prácticos eso es, más o menos, lo que ha venido ocurriendo desde que Barack Obama accedió a la presidencia en 2009. Contemplado en términos globales es muy probable que la situación geopolítica mundial haya apuntalado esta corrección de rumbo: por una parte están los puntos calientes en los que, Washington, ha estado involucrado (Afganistán, Irán, Libia, etc.) y por la otra, sus prioridades estratégicas a largo plazo, que están en Asia.

Actualmente, todo ello nos coloca en el marco de una estrategia global de soft powers ${ }^{5}$ que, de paso, parece haber

y no renovable como el petróleo. A partir de ahí explica las razones de una dependencia que considera sólida: Estados Unidos sigue siendo el principal socio comercial, petrolero y no petrolero, de Venezuela; la política de incremento de la producción petrolera de Caracas (el Plan Siembra Petrolera) tiene limitantes técnicos (la falta de liquidez y la disminución de las inversiones extranjeras); económicos (el petróleo pesado venezolano solo es refinable a costos competitivos en Estados Unidos, razón por la cual a China le saldría demasiado caro comprar grandes contingentes) y políticos (no es seguro que China, con los intereses que tiene en Estados Unidos quiera importunar más de lo debido a Washington).

55 En los últimos tiempos, Washington, parece haber esbozado algunas trazas básicas de dicha política: sólida alianza con Brasil (rubricada a través del interés común en desarrollar los agrocombustibles como fuente 
contribuido a ajustar los principios con los que funciona el lobby venezolano-americano: mayor asentamiento institucional en Estados Unidos y mayor realismo en relación a sus aspiraciones en Venezuela. En dicho contexto habría que ubicar el crecimiento, dopado por un apoyo sutil pero sin fisuras, a la candidatura opositora de Henrique Capriles.

\section{Conclusiones}

Desde que el petróleo venezolano comenzó a ser explotado a gran escala - en la década de los 1920 - el país sudamericano se convirtió en una pieza clave de las relaciones internacionales. Durante la Guerra Fría, Venezuela redobló una importancia geopolítica que la desaparición de la Unión Soviética no ha atenuado. Sigue tratándose, no en vano, de una de las grandes fuentes de reposición energética de Estados Unidos (es el cuarto exportador a dicho país).

Actualmente, Caracas, pregonará el socialismo del siglo $X X I$ pero sus hidrocarburos siguen alimentando, en los hechos, la bulímica locomotora de la primera economía capitalista mundial (29\% del PIB global). Su actual Presidente se habrá convertido, por otra parte, en una estrella mediática pero el desconocimiento - político y académico - que sigue existiendo en el mundo en torno al país sudamericano es grande, sobre todo, en términos comparados.

alternativa de energía) y vínculos comerciales estrechos con el resto de países aliados (los TLCs bilaterales sustituirían, en los hechos, al propio ALCA). 
Venezuela siempre ha sido víctima de su riqueza petrolera. Históricamente, su explotación no sólo dificultó el aprovechamiento de otros recursos naturales sino que, además, propició una sumisión política hacia el exterior que tiene escasos parangones, incluso, en el marco latinoamericano. El momento álgido de dicha realidad se vivió cuando, durante las décadas de los 1980 y los 1990, PDVSA desactivó, despolitizándola, la acción exterior del país.

La llegada de Hugo Chávez al poder, sin embargo, cambió las cosas. La petrolera nacional volvió a someterse a las directrices de un Gobierno que, no sólo retomó el control de la acción exterior, sino que la repolitizó volviendo a colocar al país en el mapa. Pese a ello, fuera de Venezuela, los estereotipos se dispararon. Contribuyeron a ello, sin duda, las dificultades de Caracas para romper el cerco informativo al que fue sometida, prácticamente desde 2001.

Anécdotas al margen, hay dos elementos que caracterizan al cambio de rumbo protagonizado por la política exterior venezolana en los últimos años: apuesta por el multilateralismo y retórica anti-imperialista. De hecho, Estados Unidos, ha dejado de ser para Caracas la metrópoli de referencia. Más bien se ha convertido en un - martiniano - Norte turbulento y brutal que, pese a todo, sigue comprando hidrocarburos y siendo el principal socio comercial no petrolero...

En dicho contexto, a pesar de que la propaganda oficial venezolana tiende a atribuir su aparente alejamiento de Washington, exclusivamente, a la reciente politización de su diplomacia petrolera, hay otros factores que, como la crisis financiera mundial o el progresivo traslado del eje geopolítico global hacia Asia, también contribuyen a explicar 
el alejamiento estadounidense, no sólo de Venezuela, sino de América Latina.

Dicho esto, cuesta creer que la proyección internacional de Venezuela hubiera sido la misma de no haber llegado Chávez a la presidencia. De hecho, si las cosas se ven desde ese punto de vista, se comprenderá por qué, aunque es cierto que los vínculos entre Caracas y Washington siguen teniendo un contenido significativo, el comportamiento político de la Venezuela Bolivariana se caracteriza por un carácter relativamente ambivalente.

Y lo calificamos de ambivalente porque, en la práctica, las posiciones de la Venezuela chavista resultan más moderadas de lo que la retórica oficial (pero, también, la mediática) dan a entender. De hecho, el Gobierno Bolivariano (muy táctico, sobre todo en el corto plazo) ha sido al mismo tiempo, pagador de deuda externa y altermundista; socio de activos financieros globales y socialista; suministrador de petróleo a Estados Unidos y anti-imperialista...

Quizás, ése sea el motivo por el que Caracas preocupa, más en el ámbito mediático, que en el político o en el diplomático occidental. Se es consciente, no en vano, de que su capacidad de influencia está condicionada por límites objetivos: la dependencia estructural de un bien fluctuante como el petróleo pero, también, la dependencia exterior que seguiría teniendo el país en caso de apostar por la exportación de bienes y/o recursos no petroleros.

Dicha conciencia no es óbice, en todo caso, para que la parte más simbólica del discurso chavista siga inquietando y en ocasiones, bastante. En el fondo, se trata de ejemplaridad: de hecho, en Europa y en Estados Unidos disgustan 
sobremanera, tanto el anticapitalismo de Chávez como sus heterodoxas amistades con personajes controvertidos de las relaciones internacionales como los Gadafi, de Libia; los El-Assad, de Siria o los Castro, de Cuba.

En el fondo, ello revela una preocupación sostenida que trasciende, incluso, el caso de la Venezuela Bolivariana: se trata de la reciente evolución de las relaciones internacionales. En dicho ámbito, pese a las apariencias, el dominio occidental comienza a ser declinante y las relaciones que Venezuela mantiene, no sólo con los llamados Rogue States sino con potencias emergentes (como China, Rusia o incluso, Irán) son sólo su síntoma más evidente.

Actualmente asistimos a una progresiva recomposición del sistema internacional en el marco del cual, la competencia por los recursos naturales, está jugando un papel esencial. En dicho contexto, América Latina, es clave: se trata, no en vano, de una región tradicionalmente exportadora de recursos naturales que, desde hace aproximadamente una década, está logrando sustraerse, al menos en parte, al férreo control político que padeció antaño.

Ese es el marco en el que se mueve la Venezuela Bolivariana: un país que, independientemente de sus subterráneas relaciones con Occidente, está logrando redimensionar su importancia geopolítica, tanto entablando relaciones diplomáticas no tradicionales, como recuperando un espíritu de integración latinoamericana que, a su vez, está contribuyendo a revalorizar el papel de América Latina (y por ende, de Brasil) en el mundo contemporáneo.

(Ciudad de México, 7 de marzo de 2012). 


\section{Referencias}

BAPTISTA, Asdrúbal. Bases cualitativas de la economía venezolana: 1830-2002. Caracas: Fundación Polar, 2006.

. El relevo del capitalismo rentístico: hacia un nuevo balance de poder. Caracas: Fundación Polar, 2006. . Teoría económica del capitalismo rentístico: economía, petróleo y renta. Caracas: IESA, 1997. BOUÉ, Juan Carlos. La internacionalización de PDVSA, una costosa ilusión. Caracas: MEM, 2004.

CORONIL, Fernando. The Magical State: nature, money and modernity in Venezuela. Chicago: University of Chicago Press, 1997.

CHOMSKY, Noam. Failed States: the Abuse of Power and the Assault of Democracy. New York: Metropolitan Books, 2006.

ELLNER, Steve; TINKER SALAS, Miguel. The Venezuelan Exceptionalism Thesis: Separating Myth from Reality. Thousand Oaks: Latin American Perspectives, v. 32, n.2, p. 5-19, 2005).

FILARDO, Leonor. Reformas monetarias ineficaces. Cedice. Caracas, 2007. Disponible em: <www.cedice.org.ve>.

FORERO, Juan. Chávez. Documents Show C.I.A. Knew of a Coup Plot in Venezuela. New York: The New York Times, (December 3, 2004). 
. Chávez. Seeking Foreign Allies, Spends Billions.

New York: The New York Times, April 4, 2006.

FUENTES, Emilio. La identidad nacional venezolana.

Caracas: FUNDAIAEDEN, 1995.

GOLINGER, Eva. Bush vs. Chávez: La guerra de Washington contra Venezuela. La Habana: José Martí, 2006.

GOLINGER, Eva. El código Chávez: descrifrando la intervención de los Estados Unidos en Venezuela. La Habana: Ciencias Sociales, 2005.

KELLY, Janet; ROMERO, Carlos A. United States and Venezuela: Rethinking a Relationship. New York : Routledge, 2002.

KOZLOFF, Nicholas. Hugo Chávez: Oil, Politics and the Challenge to U.S. New York: MacMillan, 2006.

LANDER, Edgardo. Venezuelan social conflict in a Global Context. Thousand Oaks: Latin American Perspectives, v. 32, n.2, p. 20-38, 2005).

LANDER, Luis E. La insurrección de los gerentes: PDVSA y el Gobierno de Chávez. Caracas: Revista Venezolana de Economía y Ciencias Sociales, v..10, n.2, p. 13-32, may./ ago. 2004).

LAPPER, Richard. Living with Hugo: U.S. Policy toward Hugo Chávez's Venezuela. New York: Council on Foreign Relations, 2006. 
LÓPEZ, Odalis. La 'Enfermedad Holandesa' y la economía venezolana: el periodo 1973-1982 y el colapso del 'capitalismo rentístico. Caracas: Revista Venezolana de Economía y Ciencias Sociales, v. 7, n.2, p. 67-107, may./ago 2001).

MEDINA-SMITH, Emilio. La fuga de capitales en Venezuela: 1950-1999. Caracas: BCV, 2005.

MÉNDEZ, José Luis; BUAJASÉN, José. La República de Miami. Caracas: Monteávila, 2006.

OCANDO, Casto. Antichavistas buscan apoyo en el exilio cubano. Miami: El Nuevo Herald, [(22-X-2002)].

PÁRRAGA, Marianna. \$850 millones financió Venezuela a Cuba. Caracas: El Universal, [(31-X-2005)].

SHANNON, Thomas A. Democracy in Venezuela is in Grave Peril. (Statement by Assistant Secretary of State) Washington DC: House of Representatives, 2005 (Nov.17).

SWEIG, Julia E. Can't Live with Chávez, Can't Live without Him. Los Angeles: Los Angeles Times, [2-VI- 2002)].

THR. Plan de marketing de Venezuela. Madrid, 2001.

VEGA, Iván de la. Cienciometría y política científica en la periferia: el caso de Venezuela. Caracas: Revista Espacio, v. 24, n.1, Caracas, 2003. 